\title{
Study on Seismic Fragility Analysis for Piping of CEFR
}

\author{
Zhiwei Fu ${ }^{1,2}$, Yahua Qiao ${ }^{1}$, Long Tang ${ }^{2}$, Yan Chen ${ }^{1}$, Jiaxu Zuo ${ }^{1 *}$ \\ ${ }^{1}$ Nuclear and Radiation Safety Center of MEP, Beijing, China \\ ${ }^{2}$ China Institute of Atomic Energy, Beijing, China \\ Email: *fuzhiwei@chinansc.cn
}

Received September 2013

\begin{abstract}
This paper introduces the conception of seismic fragility, gives the model of seismic fragility analysis, and places emphasis on discussing quantization process of seismic fragility parameters. Then, establishes 3D model of pipes of Chinese Experimental Fast Reactor (CEFR) accident residual heat removal system, and obtains the stresses which are essential for calculating seismic fragility parameters. Finally, combined with quantitative methods of seismic fragility, calculates the safety factors and uncertainties of CEFR pipeline, and obtains the system seismic fragility parameters: $A_{m}$ $=2.42 \mathrm{~g}, \beta \mathrm{r}=0.36, \beta \mathrm{u}=0.44, \mathrm{HCLPF}=0.65 \mathrm{~g}$. The results show that: the pipeline of CEFR accident residual heat removal system has high seismic capacity.
\end{abstract}

Keywords: Seismic Fragility; Fragility Parameter; CEFR Accident Residual Heat Removal System; 3D Model

\section{Introduction}

Liquid metal sodium is used as the coolant of China Experimental Fast Reactor (CEFR), which is different form PWR and BWR. The greatest advantage that sodium is as a heat transfer medium is that it can keep liquid in a wide temperature range, which melting point is only $97.8^{\circ} \mathrm{C}$ and high boiling point is $882.9^{\circ} \mathrm{C}[1,2]$. Another advantage of liquid sodium is its high thermal conductivity coefficient. Therefore, the structural common features of a sodium-cooled fast reactor are as follows: high temperature makes structure stiffness lower and pipe walls as possible as thin as possible, and at the same time high temperature brings thermal expansion effects. These features are bound to reduce seismic capacity of high temperature equipment $[1,2]$. So, the pipe of CEFR accident residual heat removal system with typical characteristics of sodium-cooled fast reactor is chosen to study.

Seismic fragility analysis is a probabilistic method which is used to evaluate real seismic capacity of equipment, and is a key element in seismic PSA, while seismic fragility is one of the two parameters used to quantify core damage frequency (CDF) by seismic events. In this paper, seismic fragility analysis method is researched, the three-dimensional model of system piping is build, fragility variables of piping of CEFR accident residual heat removal system are quantified, and the capacity of the piping is evaluated.

${ }^{*}$ Corresponding author.

\section{Seismic Fragility}

\subsection{Conception of Seismic Fragility}

The seismic fragility of a structure or equipment is defined as the conditional probability of its failure at a given value of ground motion value (i.e., peak ground acceleration or peak spectral acceleration at different structural or equipment frequencies) $[3,4]$. The purpose of seismic fragility is to obtain the media seismic capacity, randomness and uncertainty, and the high-confidenceof-low-probability-of-failure (HCLPF) capacity under some failure modes, and further estimate the capacity of a given component in terms of a ground motion parameter. The seismic fragility is corresponded with failure modes, so for different failures there are different fragility parameters, and different fragility curves can be obtained. Figure 1 [3] shows fragility curves for a component based on double logarithmic normal distribution under a certain failure mode.

In Figure 1, Am is the best estimate of the median ground acceleration capacity, $\beta_{\mathrm{R}}$ and $\beta_{\mathrm{U}}$ are logarithmic standard deviations with median values 1.0 respectively. One job of seismic fragility is to obtain $A_{m}, \beta_{R}$ and $\beta_{U}$ under a determined failure mode.

\subsection{Seismic Fragility Model}

The entire family of fragility curves for an element corresponding to a particular failure mode can be expressed in terms of the best estimate of the median ground 


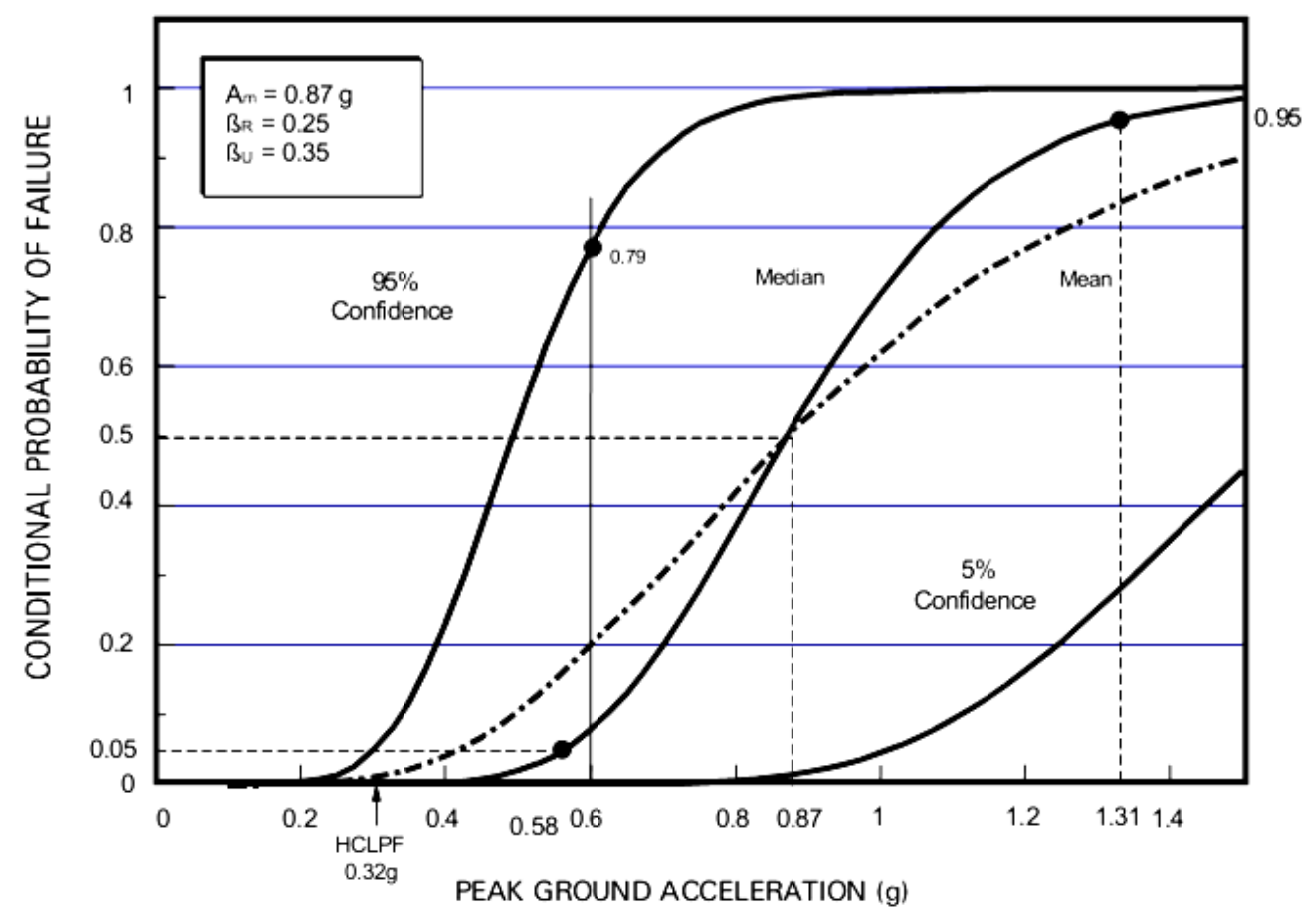

Figure 1. Mean, median, $5 \%$ non-exceedance, and $95 \%$ non-exceedance fragility curves for a component.

acceleration capacity, Am, and two random variables. Thus, the ground acceleration capacity, A, is given by (1) [4]:

$$
A=A_{m} e_{R} e_{U}
$$

in which $e_{R}$ and $e_{U}$ are random variables with median values of 1.0, representing, respectively, the inherent randomness about the median and the uncertainty in the median value. In this model, we assume that both $e_{R}$ and $e_{U}$ are lognormally distributed with logarithmic standard deviations, $\beta_{R}$ and $\beta_{U}$, respectively. So due to the assumption and the equation (1), we can obtain easily fragility curves for structures or equipment, and the conditional probability of its failure at a given value of acceleration is given by [5]:

$$
f^{\prime}=\Phi\left[\frac{\ln \left(\frac{a}{A_{m}}\right)+\beta_{U} \Phi^{-1}(Q)}{\beta_{R}}\right]
$$

in which Q is called confidence and $\Phi^{-1}[\bullet]$ is the standard Gaussian cumulative distribution of the term in brackets.

\subsection{Fragility Analysis Variables and Their Quantification Method}

Before you begin to format your paper, first write and save the content as a separate text file. Keep your text and graphic files separate until after the text has been formatted and styled. Do not use hard tabs, and limit use of hard returns to only one return at the end of a paragraph. Do not add any kind of pagination anywhere in the paper. Do

In estimating fragility parameters, it is convenient to work in terms of an intermediate random variable called the factor of safety. The factor of safety, F, on ground acceleration capacity above a reference level earthquake specified for design; e.g., the safe shutdown earthquake level specified for design, A, is defined as follows $[3,4]$ :

$$
F=\frac{A}{A_{S S E}}
$$

in which $\mathrm{A}$ is the actual capacity on acceleration motion ground. This relationship is typically expanded to identify the conservatism or factor of safety in both the strength and the response, as:

$$
F=F_{C} F_{R}
$$

And so the median factor of safety, Fm, can be directly related to the median ground acceleration capacity, Am, as:

$$
A_{m}=F_{m} A_{S S E}
$$

For equipment, the factor of safety consists of structure response factor, equipment response factor and capacity factor, as:

$$
F_{E}=F_{R S} F_{R E} F_{C}
$$

Generally, the elements which can affect structure re- 
sponse involve ground motion (such as earthquake response spectrum shape, horizontal direction peak response, and vertical component response), damping, modeling, mode combination, time history simulation, foundation-structure interaction, and earthquake combination. The elements which can affect equipment response, similar to the above, include qualification method, damping, modeling, mode combination, earthquake combination. Note that in order to avoid duplicating, earthquake combination only is considered in equipment response $[6,7]$.

The capacity factor $\mathrm{F}_{\mathrm{C}}$ for the equipment is the ratio of the acceleration level at which the equipment ceases to perform its intended function to the seismic design level. And the factor FC can be calculated by the strength factor FS and the inelastic energy absorption factor $F_{\mu}$, as (7) [5].

$$
\mathrm{F}_{\mathrm{C}}=\mathrm{F}_{\mathrm{S}} \mathrm{F}_{\mu}
$$

The strength factor, FS, represents the ratio of ultimate strength (or strength at loss-of-function) to the stress calculated for acceleration at safety shutdown earthquake $\left(\mathrm{A}_{\mathrm{SSE}}\right)$. In calculating the value of $\mathrm{F}_{\mathrm{S}}$, the non-seismic portion of the total load acting on the structure is subtracted from the strength as follows:

$$
\mathrm{F}_{\mathrm{S}}=\frac{\mathrm{S}-\mathrm{P}_{\mathrm{N}}}{\mathrm{P}_{\mathrm{T}}-\mathrm{P}_{\mathrm{N}}}
$$

where $S$ is the strength of the structural element for the specific failure mode, $\mathrm{P}_{\mathrm{N}}$ is the normal operating load (i.e., dead load, operating temperature load, etc.) and $\mathrm{P}_{\mathrm{T}}$ is the total load on the structure (i.e., sum of the seismic load for SSE and the normal operating load). For higher earthquake levels, other transients may have a high probability of occurring simultaneously with the earthquake. The definition of in such cases should be extended to include the loads from these transients.

Randomness and uncertainty are the two important parameters in seismic fragility analysis, so when determining the safety factors the two parameters should be determined too [7].

\section{Stress Calculation of CEFR Accident Residual Heat Removal System Piping}

\subsection{Basic Condition of the Piping}

CEFR accident residual heat removal system has two loops, and one loop mainly includes an independent heat exchanger, an air heat exchanger and piping. The layout of one loop is as Figure 2 [2].

The material of the piping is $304 \mathrm{H}$, and the size of the piping is as Figure 2. The piping material of argon system for accident residual heat removal system is $304 \mathrm{~L}$, and the piping size is $\Phi 48 \times 4$. The piping material of sodium analysis and monitoring system for accident

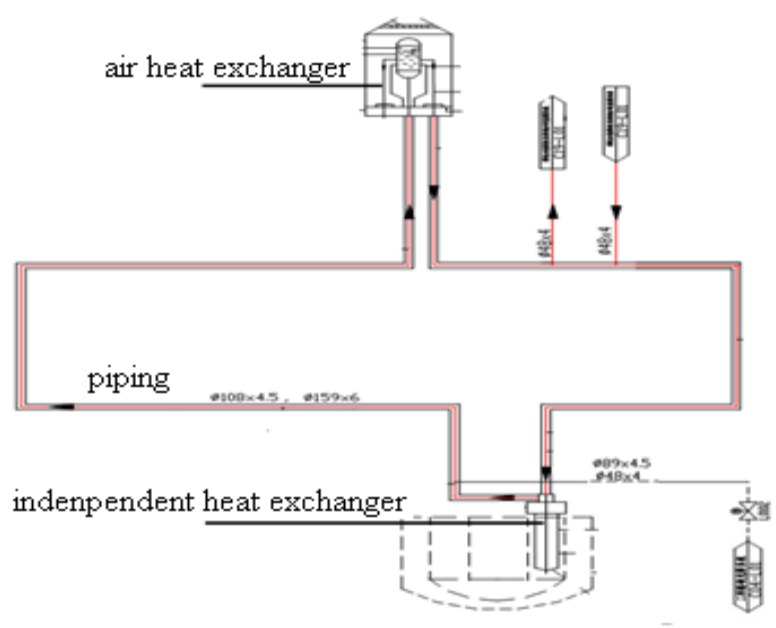

Figure 2. Layout of one loop's piping of CEFR accident residual heat removal system.

residual heat removal system piping is $304 \mathrm{H}$, and the size of double piping are $\Phi 108 \times 4.5$ and $\Phi 48 \times 4$.

\subsection{Modeling for the Piping}

The finite element method is used, and the AutoPIPE software is chosen as analysis tool. The $3 \mathrm{D}$ continuous pipeline is dispersed many space tube units, and the units are connected by nodes. The connection points of equipment and piping are taken as boundary conditions, and the displacement is given according to the thermal expansion. The valves are simulated by valve units taking account into the impact of the quality of electric head. The treatment of double pipe is built two tubes, one of which is a relatively small amount of displacement, the pipeline where there is a shim in practice is connected with the guide frame. The model of one loop is shown in Figure 3.

\subsection{Stress Calculation and the Selection of Fragile Parts}

To calculate the capacity factor of the piping, the stresses generated by both normal operating conditions and safety shutdown earthquake (SSE) load are needed, so the loads should be applied to the model.

\subsubsection{Determination and Loading of Loads}

Assumed that when the earthquake occurring, the reactor is in normal operation condition, and the system is in the normal standby condition, so the loads on the pipe can be determined when the earthquake occurring.

1) Loads under normal operation condition Loads under normal operation condition include pressure $0.402 \mathrm{MPa}$, weight, the constraint force and thermal load of $485^{\circ} \mathrm{C}$. Put the combination of these loads to the model, then can get the stress $\sigma_{\mathrm{N}}$. 


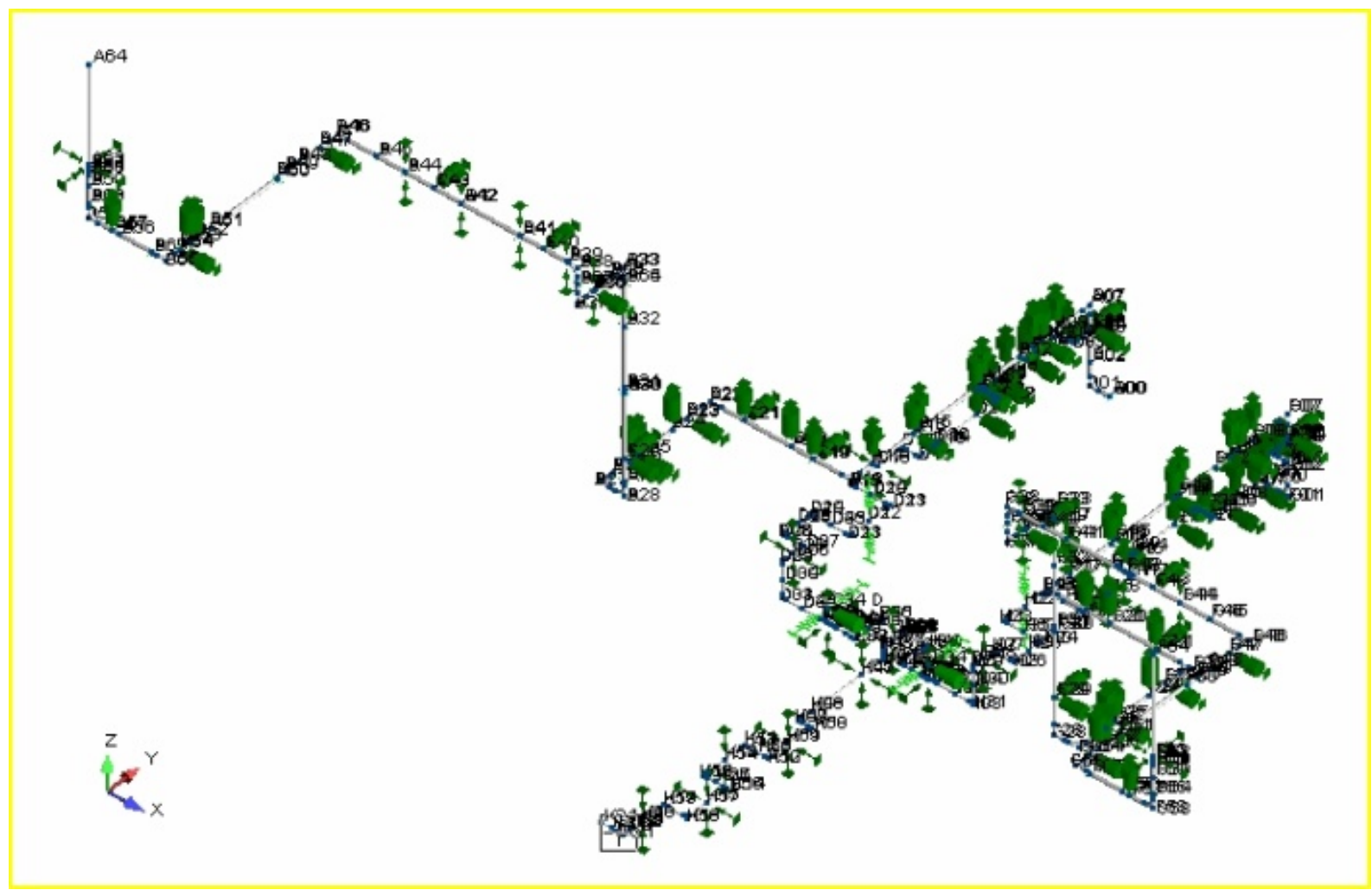

Figure 3. Model of piping.

\section{2) Loads under SSE condition}

According to above assumption, loads under SSE condition include the load caused by the SSE in addition to the loads under normal operation condition. The load caused by the SSE can be loaded by seismic response spectrum, which comes from reference [2]. The spectrums used in the calculation are about four high levels $22.4 \mathrm{~m}, 26.6 \mathrm{~m}, 30.8 \mathrm{~m}$ and $35 \mathrm{~m}$, and each level has three response spectrums, two horizontal and one vertical. The response spectrums about 5\% damping are put in the AutoPIPE software, then the seismic response spectrum about SSE can be determined as Figure 4.

\subsubsection{Fragile Points and Their Stresses}

When determining the fragile points, two methods are used. One method is to choose the points where the stress $\sigma_{\mathrm{SSE}}$ caused by the SSE load is the maximum, the other is to choose the points where the stress $\sigma_{\mathrm{N}+\mathrm{SSE}}$ caused by both the loads in the normal operation condition and the SSE load is maximum. The points determined by the two methods are often not the same point, because the thermal expansion effects have been considered in the design stage.

The SSE load and the combination of SSE load and the normal loads loaded on the model one after another, the points inside and outside the pipe where the stresses are maximum are choose respectively as Figure $\mathbf{5}$ and
Figure 6. The fragile points and their stresses are shown in Table 1.

\section{Fragility Analysis and Calculation of CEFR Piping}

\subsection{Calculation of Response Factor}

Building structural response factor is calculated by NUREG0098 [8] factor median spectrum proportion and RG1.60 [9] spectrum proportion, and the piping response factor is calculated using the NUREG0098 median spectrum proportion and design floor response spectrum. The calculated median factor and uncertainty are as follows:

Building located on the fifth floor structural response median factor, randomness and uncertainty are $\mathrm{F}_{\mathrm{SR}}=1.0$, $\beta_{\mathrm{RSR}}=0.31, \beta_{\text {USR }}=0.33$.

Building located on the eighth floor structural response median factor, randomness and uncertainty are $\mathrm{F}_{\mathrm{SR}}=0.7$, $\beta_{\mathrm{RSR}}=0.31, \beta_{\mathrm{USR}}=0.33$.

When calculating the response factor of the pipe, the response factor is only considered in damping factor, and the randomness and uncertainty are only considered in other factors. The calculated damping factors and uncertainty are as follows:

The pipe located on the fifth floor damping factor and uncertainty are $\mathrm{F}_{\mathrm{D}}=1.8, \beta_{\mathrm{UD}}=0.22$; The pipe located on the eighth floor damping factor and uncertainty are 


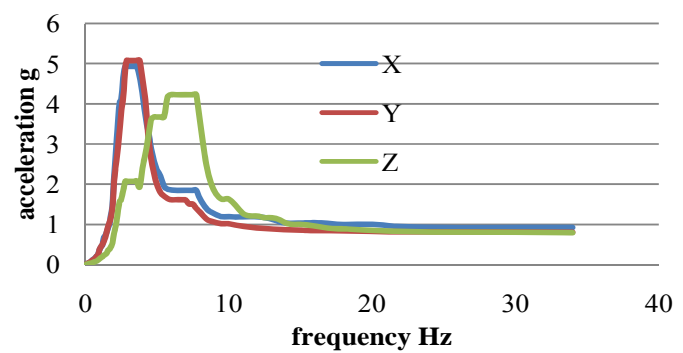

Figure 4. seismic response spectrum by SSE.

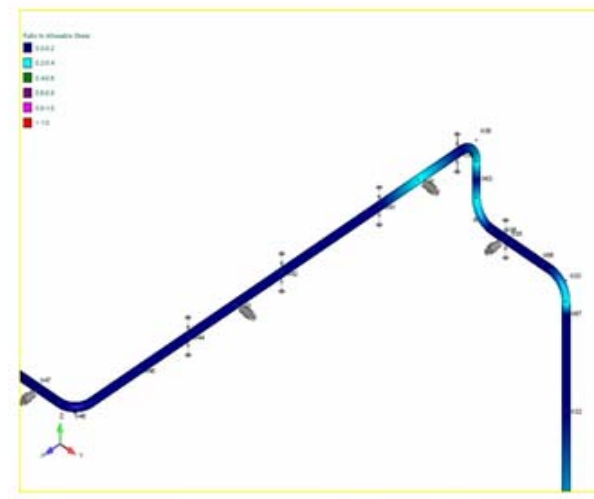

Figure 5. Points of inside/outside tube where stress by SSE load is maximum.
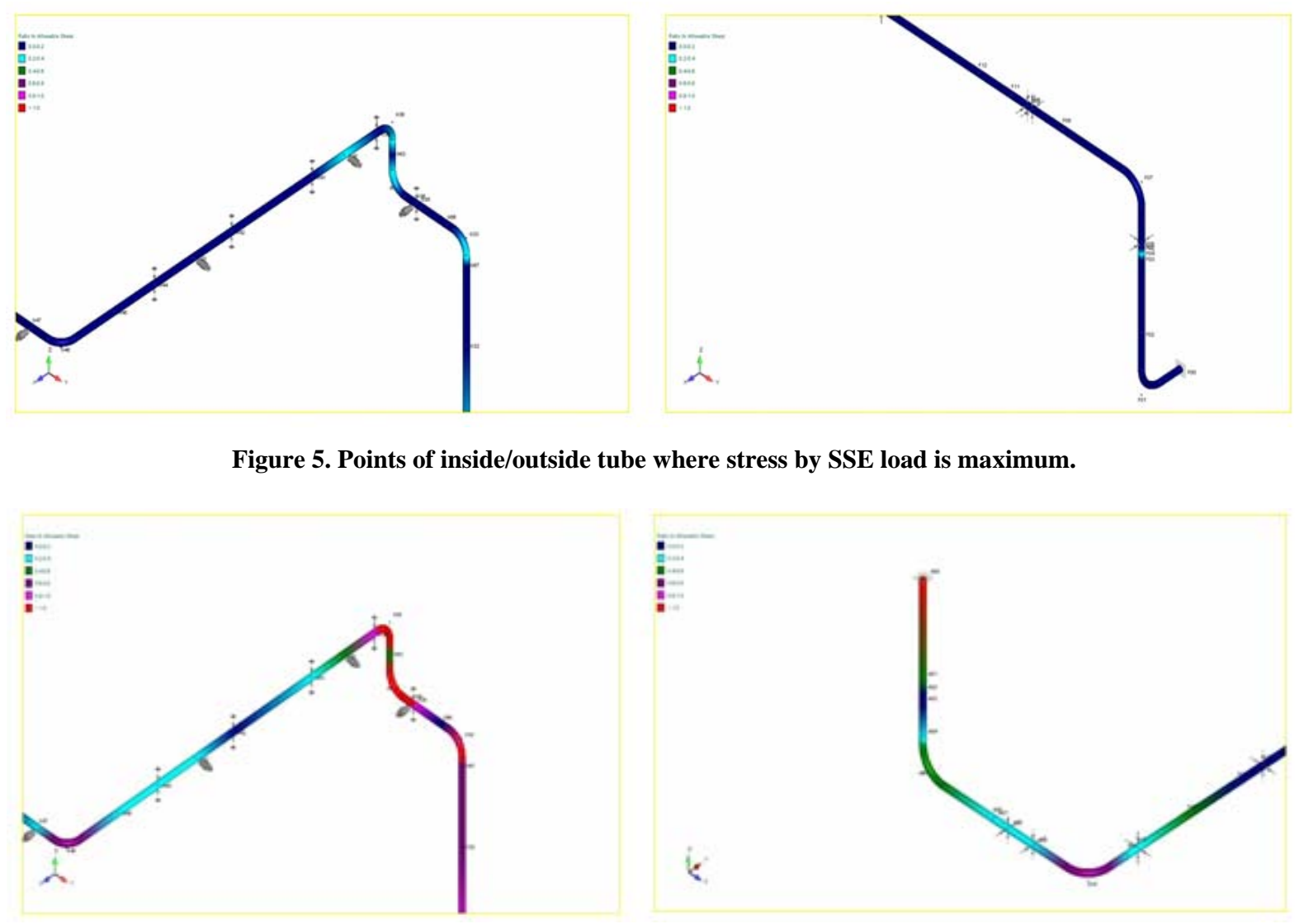

Table 1. Fragile points and their stresses.

\begin{tabular}{cccccc}
\hline \multirow{2}{*}{ Loads } & Point & \multicolumn{2}{c}{$\begin{array}{c}\text { Outside tube } \\
(\mathrm{MPa})\end{array}$} & \multicolumn{2}{c}{$\begin{array}{c}\text { Inside tube } \\
(\mathrm{MPa})\end{array}$} \\
\cline { 3 - 6 } & & $\sigma_{\mathrm{SSE}}$ & $\sigma_{\mathrm{N}}$ & $\sigma_{\mathrm{SSE}}$ & $\sigma_{\mathrm{N}}$ \\
\hline SSE load & G37/8 $8^{\text {th }}$ floor $)$ & 52 & 123 & 59 & 97 \\
$\begin{array}{c}\text { Normal loads } \\
+ \text { SSE load }\end{array}$ & G35(5 $5^{\text {th }}$ floor $)$ & 16 & 249 & 59 & 97 \\
\hline
\end{tabular}

Figure 6. Points of inside/outside tube where stress by normal loads and SSE load is maximum.

$\mathrm{F}_{\mathrm{D}}=1.6, \beta_{\mathrm{UD}}=0.24$.

So the piping response median factors and uncertainty are as follows:

The pipe located on the fifth floor median factor and uncertainty are $\mathrm{F}_{\mathrm{RE}}=1.8, \beta_{\mathrm{RRE}}=0.18, \beta_{\mathrm{URE}}=0.26$.

The pipe located on the eighth floor median factor and uncertainty are $\mathrm{F}_{\mathrm{RE}}=1.6, \beta_{\mathrm{RRE}}=0.18, \beta_{\mathrm{URE}}=0.28$.

\subsection{Calculation of Capacity Factor}

The pipe material is $304 \mathrm{H}$, according to the reference [5], the median material yield strength is $37 \mathrm{ksi}(255 \mathrm{MPa})$, and the uncertainty is 0.13 ; the median limit strength is $84 \mathrm{ksi}(579 \mathrm{MPa})$, and the uncertainty is 0.07 . According to the standard of ASME [10], the normal loads + SSE load should belong to the $\mathrm{C}$ condition, and the allowable limit is 2.25 times allowable yield strength, but not more than 1.8 times ultimate strength.

The pipe failure is the ductility failure, inelastic energy absorption should be considered. The inelastic energy absorption factor is choose form reference [11], $\mathrm{F} \mu=$ 1.25 , then the uncertainty is calculated, $\beta_{U \mu}=0.1$. The strength factors of the pipe are calculated by eq- 8 , where the strength is $574 \mathrm{MPa}, \mathrm{PN}$ is $\sigma_{\mathrm{N}}$, and $\mathrm{P}_{\mathrm{T}}-\mathrm{P}_{\mathrm{N}}$ is $\sigma_{\mathrm{SSE}}$. The calculated strength factor, capacity factor and uncertainty are shown in Table 2.

\subsection{Fragility Analysis and Calculation for Piping}

According to above equations and data, the fragility 
Table 2. Quantification results of capacity factor, strength factor and uncertainty.

\begin{tabular}{|c|c|c|c|c|c|c|c|}
\hline \multirow{2}{*}{ loads } & \multirow{2}{*}{ points } & \multicolumn{3}{|c|}{ Outside tube $(\mathrm{MPa})$} & \multicolumn{3}{|c|}{ Inside tube (MPa) } \\
\hline & & $\mathrm{F}_{\mathrm{S}}$ & $\mathrm{F}_{\mathrm{C}}$ & $\beta_{\mathrm{U}_{\mathrm{C}}}$ & $\mathrm{F}_{\mathrm{S}}$ & $\mathrm{F}_{\mathrm{C}}$ & $\beta_{\mathrm{U}_{\mathrm{c}}}$ \\
\hline Normal loads + SSE load & G35(5th floor) & 20.31 & 25.38 & 0.16 & 8.08 & 10.1 & 0.16 \\
\hline
\end{tabular}

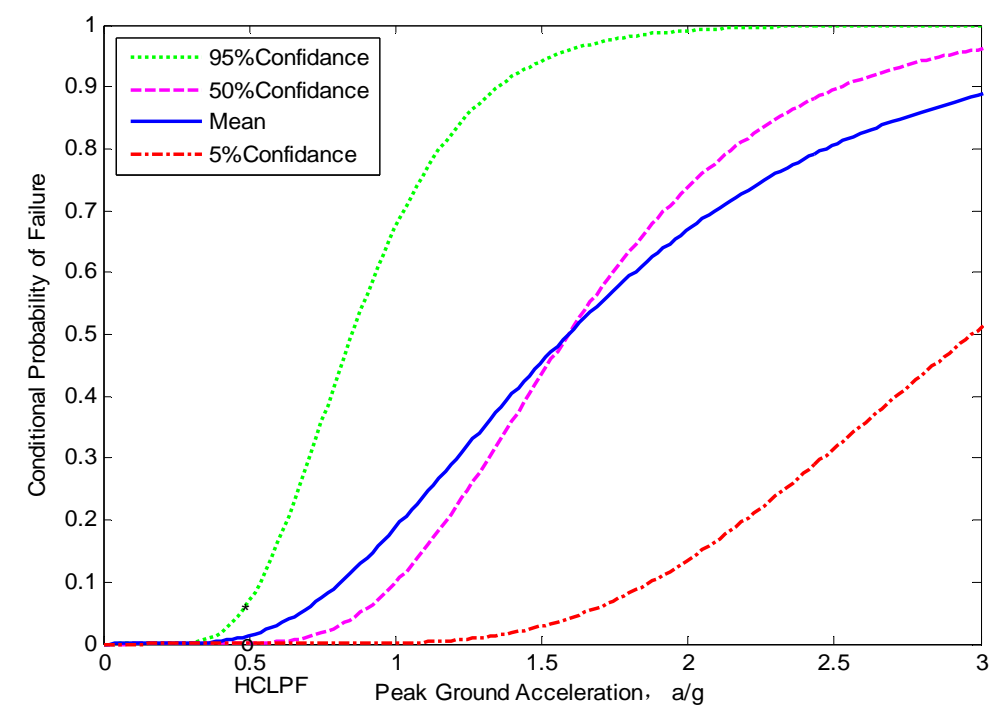

Figure 7. Fragility curves of the piping.

parameters of the lower capacity point conservatively selected as the fragility parameters of piping, the final fragility parameters of piping are as follow:

$$
\begin{aligned}
& \mathrm{A}_{\mathrm{m}}=\mathrm{F}_{\mathrm{m}} \mathrm{A}_{\mathrm{SSE}}=2.42(\mathrm{~g}) \\
& \beta_{R}=\sqrt{{\beta_{R S R}^{2}+{\beta_{R R E}}^{2}}^{2}=0.36} \\
& \beta_{U}=\sqrt{{\beta_{U S R}^{2}+\beta_{U R E}^{2}+{\beta_{U C}}^{2}}^{2}=0.44} \\
& \mathrm{HCLPF}_{50}=\mathrm{A}_{\mathrm{m}} e^{-1.65 \beta_{\mathrm{R}}} e^{-1.65 \beta_{\mathrm{U}}}=0.65(\mathrm{~g})
\end{aligned}
$$

Figure 7 shows the fragility curves of piping according to the calculated fragility parameters.

\section{Conclusions}

This paper studies the analysis method of seismic fragility, and using the method to calculate the seismic fragility parameters for the piping of CEFR accident residual heat removal system. The main results are as follows:

1) The calculated seismic fragility parameters for the piping of CEFR accident residual heat removal system are $A_{m}=2.42 \mathrm{~g}, \beta r=0.36$ and $\beta u=0.44$, and the HCLPF capacity is $0.65 \mathrm{~g}$.

2) Compared with CEFR SSE, the results indicate that the piping of CEFR accident residual heat removal system has stronger seismic capacity.
3) This paper has used the NUREG0098 reference spectrum, rather than the actual site probability hazard curve, which must cause the calculated results different from actual values.

4) In this paper, the data of some safety factors and uncertainty are recommended by references, and these data are different form real data of power plant, which is the focus of future research too.

\section{Acknowledgements}

Thanks for Professor Zhang Donghui, Professor Zhang Chunming and senior engineer Li Tieping who have given important guidance and help. At the same time this paper is sponsored by Large-scale Advanced Pressurized Water Reactor Power Plant project of National Science and Technology Major Project (2013ZX06002001).

\section{REFERENCES}

[1] Z. W. Fu, "Study on Seismic Fragility Analysis for CEFR Accident Residual Heat Removal System," China Institute of Atomic Energy, Beijing, 2013.

[2] CIAE, "Final Safety Analysis Report for China Experimental Fast Reactor," China Institute of Atomic Energy, Beijing, 2008.

[3] EPRI, EPRI-1002989, "Seismic Probabilistic Risk Assessment Implementation Guide," 2009. 
[4] EPRI, EPRI 1019200, "Seismic Fragility Application Update Guide,” Palo Alto, 2009.

[5] EPRI, EPRI-TR-103959, "Methodology for Developing Seismic Fragilities,” Palo Alto, 1994.

[6] EPRI, EPRI-1002988, "Seismic Fragility Application Guide," Electric Power Research Institute (EPRI), Palo Alto, 2002.

[7] Z. W. Fu, D. H. Zhang, C. M. Zhang, et al., "Study on Equipment Seismic Fragility Analysis Method," Nuclear Science and Engineering, Vol. 33, No. 2, 2013, pp. 213218.
[8] N. M. Newmark and W. J. Hall, "Development of Criteria for Seismic Review of Selected Nuclear Power Plants," NUREG/CR-0098, 1978.

[9] USNRC, "Regulatory Guide 1.60 Design Response Spectra for Seismic Design of Nuclear Power Plants," 1973

[10] ASME, “ASME II-D Performance," 2004.

[11] DOE, "Natural Phenomena Hazard Design and Evaluation Criteria for Department of Energy Facilities," DOESTD-1020-2002: DOE STANDARD, 2002. 